\title{
Secagem de polpas de frutas em leite de jorro. Efeitos da adição de leites vegetal e animal e da proteína isolada de leite no desempenho do processo e qualidade do produto em pó produzido
}

\author{
S. M. de PONTES JÚNIOR ${ }^{1}$, S. C. M. DANTAS ${ }^{1}$, T. M. DELMIRO ${ }^{1}$ e M. F. D. de \\ MEDEIROS $^{1}$ \\ ${ }^{1}$ Universidade Federal do Rio Grande do Norte, Departamento de Engenharia Química \\ E-mail para contato: mariadefatima@eq.ufrn.br
}

\begin{abstract}
RESUMO - Diversos são os estudos sobre alternativas para produção de polpas de frutas em pó, nos quais se buscam melhorias nas técnicas de secagem para aumentar o rendimento da produção sem danificar a qualidade do produto. Neste trabalho, estudou-se a secagem de polpas de frutas (goiaba, acerola e pitanga) em leito de jorro com partículas inertes, com e sem adição de leite de vaca e de arroz, utilizando-se como adjuvante a proteína isolada do leite. Os ensaios foram realizados à $70{ }^{\circ} \mathrm{C}$, velocidade do ar de $1,02 \pm 0,09 \mathrm{~m} / \mathrm{s}$ dentro da coluna e carga de inerte de $2500 \mathrm{~g}$, com alimentação intermitente das polpas ou das misturas. Foram determinados o rendimento da produção e as características do pó como forma de avaliar o desempenho do processo e qualidade do produto. Os melhores rendimentos foram obtidos para as seguintes formulações: goiaba e leite de vaca $(40,63 \%)$, acerola, leite de vaca e proteína $(38,88 \%)$ e pitanga, leite de vaca e proteína $(38,02 \%)$. Os produtos finais apresentaram umidade e atividade de água adequadas para conservação e armazenamento. Os resultados alcançados indicam que dependendo das características da fruta processada a adição de leite animal ou vegetal tendo como adjuvante a proteína isolada do leite pode melhorar a performance da secagem de polpas de frutas em leito de jorro.
\end{abstract}

\section{INTRODUÇÃO}

A fruticultura e a pecuária do leite são duas atividades de fundamental importância para o setor agrícola brasileiro. Ambas são responsáveis pelo desenvolvimento de várias regiões do nosso país e, principalmente, para o Nordeste, constituem-se em fonte de renda e sobrevivência para a agricultura familiar. Contudo, uma considerável parte dessa produção se perde por danos durante as etapas de todo o processo produtivo e o transporte. Técnicas de conservação e produção de alimentos que possibilitam o aproveitamento simultâneo da fruta e do leite por longos períodos tem sido muito utilizada na indústria de laticínios, com destaque para a produção de iogurtes, sorvetes e doces caseiros. Todavia, devido aos problemas de alergia ao leite bovino, em muitos produtos o leite bovino é substituído por "leites vegetais", com destaque para o leite de soja.

Os métodos mais empregados para conservação de alimentos líquidos ou pastosos é a secagem por atomização, liofilização, em camada de espuma e em leito fluidizado ou de jorro. Nestes processos, o produto é obtido na forma de pó com elevado valor agregado. O leito de jorro é um processo que promove a evaporação da quantidade de água presente no alimento, 
produzindo um pó estável com baixas perdas de vitaminas e nutrientes (Souza, 2009). Oferece como vantagens o baixo custo de aquisição e instalação e a facilidade de operação, mas apresenta problemas de ampliação de escala.

Tem sido recorrente o estudo da viabilidade do leito de jorro para a produção de frutas em pó, o que leva, também, à busca de novas alternativas para substituição de aditivos a fim de aumentar do rendimento do processo sem que haja o comprometimento da qualidade do produto. Medeiros (2001) propôs a utilização de aditivos como lipídios, amido e pectina, em quantidades que reproduzissem uma composição ótima ajustada para a secagem de frutas tropicais em leito de jorro. Pesquisas mais atuais comprovam o maior rendimento do leito de jorro na secagem de polpas de amora e de graviola com adição de leite de vaca (Braga, 2014; Machado, 2015).

O uso de proteínas isoladas de leite como aditivo na secagem de polpas de frutas em secador por atomização tem sido apresentado como forma de tornar o material menos susceptível aos efeitos que a temperatura de secagem pode provocar. Um dos efeitos mais comuns e indesejados é a pegajosidade, responsável pelo acúmulo de material nas paredes do secador. No leito de jorro, os problemas se agravam uma vez que o material aderido às partículas inertes pode comprometer a circulação de sólidos provocando o colapso do jorro. A utilização dessas proteínas se justifica por sua capacidade de elevar a temperatura de transição vítrea do material em função de sua característica tensoativa na interface ar/água, o que causa uma proteção ao material e evita uma adesão entre partículas. (Fang e Bandhari, 2012).

Dentro dessa perspectiva do uso de proteínas como aditivo e do leite como ingrediente, objetiva-se estudar a viabilidade da secagem de polpas de frutas e misturas de polpas com leite de vaca e de arroz com e sem adição da proteína isolada do leite no secador de leite de jorro. Alguns trabalhos recentes já empregam e avaliam o desempenho de secagem com o uso de leites (Machado, 2015; Braga, 2014; Catelam, 2010) ou da proteína do leite como agente adjuvante (Fang e Bandhari, 2012).

\section{MATERIAS E MÉTODOS}

\subsection{Materiais}

As misturas foram preparadas pela combinação das polpas (acerola, goiaba e pitanga) com leite de vaca integral ou leite de arroz em pó reconstituído e a proteína isolada do leite. As formulações foram elaboradas conforme descrito na tabela 1 abaixo. O preparo se deu pela pesagem dos componentes individuais (polpa in natura e aditivos) em uma balança analítica, seguida da homogeneização dos componentes, sob agitação constante em um liquidificador doméstico por um tempo total de 1 minuto. Como material inerte, utilizou-se uma carga de partículas de $2500 \mathrm{~g}$ de polietileno de alta densidade, de diâmetro igual a 3,2 $\pm 0,05 \mathrm{~mm}$ com densidade real de $0,875 \pm 0,468 \mathrm{~g} / \mathrm{cm}^{3}$.

A umidade das misturas e dos pós foram determinadas em balança de infravermelho. Os sólidos solúveis foram medidos em refratômetro digital calibrado com água destilada e para a determinação da atividade de água dos pós utilizou-se um analisador de atividade de água do tipo AQUALAB 
Tabela 1 - Formulação das misturas

\begin{tabular}{lccc}
\hline Formulação & \% Polpa & \% Leite & \% proteína do leite* \\
\hline Goiaba/proteína do leite & 100 & - & 1 \\
Goiaba/leite de arroz & 70 & 30 & - \\
\hline Goiaba/leite de arroz/proteína do leite & 70 & 30 & 1 \\
\hline Goiaba/leite de vaca & 70 & 30 & - \\
\hline Goiaba/leite de vaca/proteína do leite & 70 & 30 & 1 \\
Acerola/proteína do leite & 100 & - & 1 \\
Acerola/leite de arroz & 70 & 30 & - \\
Acerola/leite de arroz/proteína do leite & 70 & 30 & 1 \\
Acerola/leite de vaca & 70 & 30 & - \\
\hline Acerola/leite de vaca/proteína do leite & 70 & 30 & 1 \\
\hline Pitanga/proteína do leite & 100 & - & 1 \\
\hline Pitanga/leite de arroz & 70 & 30 & - \\
\hline Pitanga/leite de arroz/proteína do leite & 70 & 30 & 1 \\
\hline Pitanga/leite de vaca & 70 & 30 & - \\
\hline Pitanga/leite de vaca/proteína do leite & 70 & 30 & 1 \\
\hline
\end{tabular}

* Percentual considerando a massa total da mistura polpa/leite.

\subsection{Ensaios de secagem}

A secagem foi realizada em leito de jorro por gotejamento das misturas dentro da coluna. Na figura1, encontra-se o sistema que compõe o leito de jorro:

Figura 1 - Unidade de secagem em leite de jorro

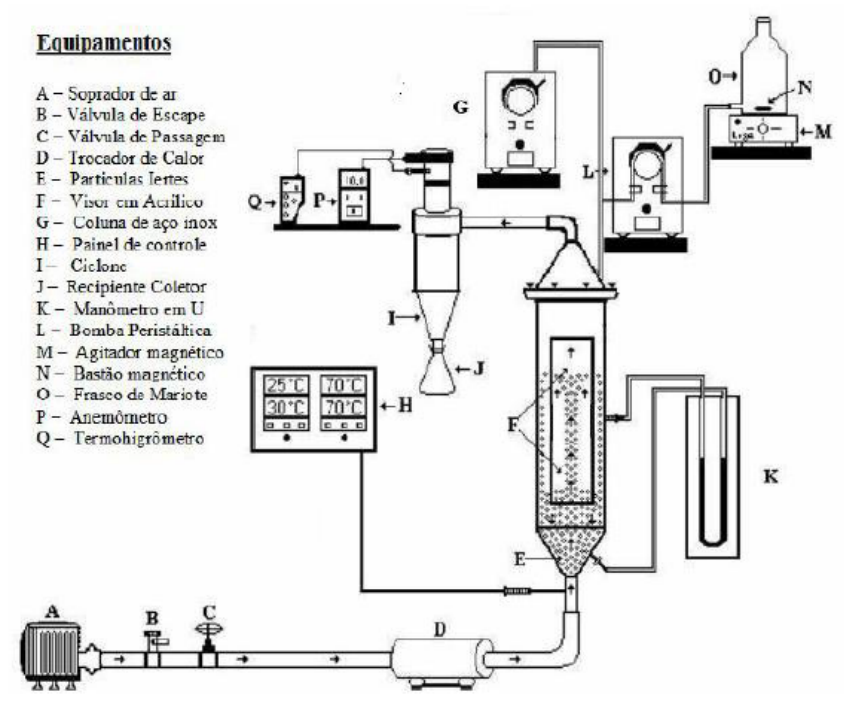


As condições de secagem foram: vazão alimentação das misturas de $7,10 \pm 1,37$ $\mathrm{mL} / \mathrm{min}$, por gotejamento em um tempo de seis minutos com intermitência de oito minutos, velocidade do ar na coluna de $1,02 \pm 0,09 \mathrm{~m} / \mathrm{s}$ e temperaturas de entrada do ar de $70^{\circ} \mathrm{C}$.

\section{RESULTADOS E DISCUSSÃO}

$\mathrm{Na}$ secagem das polpas in natura com adição de $1 \%$ de proteína de leite não foram obtidos pós e o jorro colapsou nas primeiras alimentações. Os resultados obtidos nos demais experimentos são apresentados na figura $2 \mathrm{a}$, b e c na tabela 2 .

Figura 2 - Gráficos das secagens das frutas

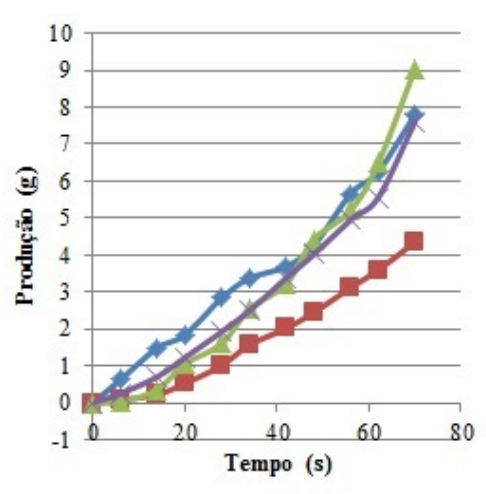

(a)

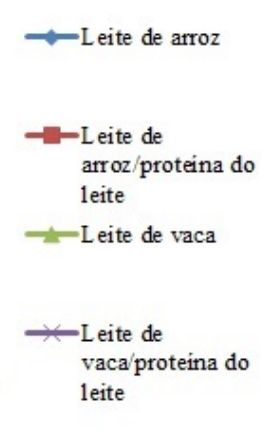

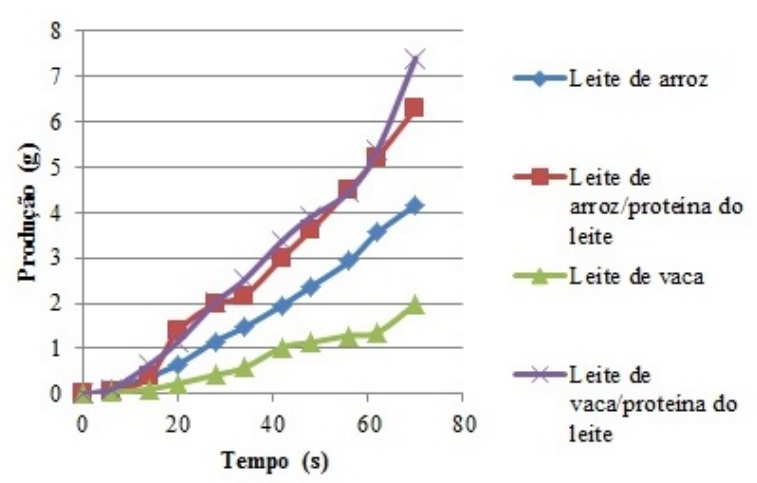

(b)

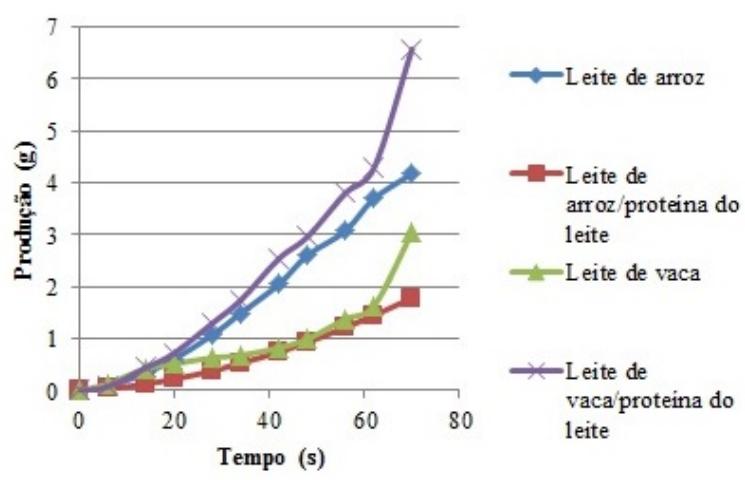

(c)

De acordo com os resultados observados na figura 2 (a) e tabela 2, a secagem da polpa de goiaba apresentou razoável produção de pó e bom rendimento quando processada com adição do leite de vaca integral e com a proteína, embora esse acréscimo aparentemente não tenha interferido positivamente na produção de pó. Na secagem da polpa de acerola referente a figura 2 (b) e tabela 2, observam-se bons resultados nas misturas com ambos os leites e adição da proteína do leite com rendimento superior a $38 \%$, valor considerado elevado tendo em vista a dificuldade da secagem da polpa desta fruta em virtude do elevado teor de açúcares redutores em sua composição. A secagem da pitanga exibiu resultados semelhantes aos da secagem da polpa da acerola para a mistura da polpa com o leite de vaca e a proteína do leite, com um rendimento em torno de $38 \%$, de acordo com a figura 2 (c). Entretanto, na substituição do leite de vaca pelo leite de arroz reconstituído, houve uma queda da produção de pó com rendimento de $7,76 \%$. 
XI Congresso Brasileiro de Engenharia Química em Iniciação Científica Unicamp - Campinas - SP 19 a 22 de julho de 2015

Analisando-se os resultados relativos à caracterização do pó apresentados na tabela 2 , percebe-se que todos os pós apresentaram baixa umidade e atividade de água dentro dos limites em que há estabilidade microbiológica.

Tabela 2 - Produção, rendimento e caracterização das misturas processadas e pós produzidos

\begin{tabular}{|c|c|c|c|c|c|c|}
\hline Formulações & $\begin{array}{c}\text { Sólidos } \\
\text { Totais } \\
(\%) \\
\end{array}$ & $\begin{array}{c}\text { Sólidos } \\
\text { solúveis } \\
\text { ('Brix) }\end{array}$ & $\begin{array}{c}\text { Atividade } \\
\text { de água } \\
\left(\mathrm{a}_{\mathrm{w}}\right) \\
\end{array}$ & $\begin{array}{c}\text { Umidade } \\
\text { do pó } \\
(\%) \\
\end{array}$ & $\begin{array}{c}\text { Produção } \\
\text { de pó (g) }\end{array}$ & $\begin{array}{c}\text { Rendimento } \\
(\%)\end{array}$ \\
\hline $\begin{array}{l}\text { Goiaba/leite de } \\
\text { arroz }\end{array}$ & 16,51 & 14,35 & 0,297 & 4,31 & 7,81 & 16,51 \\
\hline $\begin{array}{l}\text { Goiaba/leite de } \\
\text { arroz/proteína } \\
\text { do leite }\end{array}$ & 16,51 & 15,14 & 0,291 & 3,02 & 4,35 & 12,79 \\
\hline $\begin{array}{l}\text { Goiaba/leite de } \\
\text { vaca }\end{array}$ & 11,4 & 9,06 & 0,331 & 5,16 & 9,05 & 40,63 \\
\hline $\begin{array}{l}\text { Goiaba/leite de } \\
\text { vaca/proteína } \\
\text { do leite }\end{array}$ & 12,51 & 12,13 & 0,371 & 5,41 & 7,62 & 33,07 \\
\hline $\begin{array}{l}\text { Acerola/leite de } \\
\text { arroz }\end{array}$ & 14,60 & 12,89 & 0,320 & 4,70 & 4,16 & 12,79 \\
\hline $\begin{array}{l}\text { Acerola/leite de } \\
\text { arroz/proteína } \\
\text { do leite }\end{array}$ & 16,31 & 14,52 & 0,322 & 3,24 & 6,29 & 14,15 \\
\hline $\begin{array}{l}\text { Acerola/leite de } \\
\text { vaca }\end{array}$ & 9,71 & 7,22 & 0,402 & 6,35 & 1,99 & 9,14 \\
\hline $\begin{array}{l}\text { Acerola/leite de } \\
\text { vaca/proteína } \\
\text { do leite }\end{array}$ & 10,60 & 9,08 & 0,315 & 5,13 & 7,39 & 38,88 \\
\hline $\begin{array}{l}\text { Pitanga/leite de } \\
\text { arroz }\end{array}$ & 11,00 & 10,72 & 0,308 & 2,40 & 4,18 & 13,31 \\
\hline $\begin{array}{l}\text { Pitanga/leite de } \\
\text { arroz/proteína } \\
\text { do leite }\end{array}$ & 12,09 & 12,03 & 0,354 & 5,26 & 1,78 & 7,76 \\
\hline $\begin{array}{l}\text { Pitanga/leite de } \\
\text { vaca }\end{array}$ & 9,51 & 6,83 & 0,330 & 5,01 & 3,05 & 16,73 \\
\hline $\begin{array}{l}\text { Pitanga/leite de } \\
\text { vaca/proteína } \\
\text { do leite }\end{array}$ & 9,40 & 6,94 & 0,301 & 4,34 & 6,58 & 38,02 \\
\hline
\end{tabular}

\section{CONCLUSÃO}

De uma forma geral, a adição do leite vegetal ou animal facilitou o processo de secagem das polpas de frutas. Com relação à adição da proteína de leite, percebe-se que a adição desse adjuvante promoveu um aumento no rendimento quando foi processada a 
mistura de polpa de acerola com ambos os leites, enquanto para a pitanga o mesmo efeito foi observado apenas na secagem da mistura da polpa com o leite de vaca. Para a polpa de goiaba com leite, a adição da proteína não melhorou o rendimento do processo. Conclui-se que os diferentes comportamentos observados para cada fruta estão relacionados com a sua composição. Todavia, a utilização da proteína do leite adicionada às misturas de polpas e leite dependendo da composição destas, pode ser uma alternativa para promover o aumento na produção de pó mantendo a qualidade do produto, recomendando-se, portanto, sua utilização como adjuvante nos processos de secagem.

\section{REFERENCIAS}

BRAGA, M. B. Obtenção de mistura leite-amora preta em pó por secagem em leito de jorro. 2014. 160f. Tese (Doutorado em Engenharia Química). Universidade Estadual de Campinas Faculdade de Engenharia Química. São Paulo, Campinas.

CATELAM, K. T. Estudo da Influência da proporção de um “mix” leite/polpa de maracujá na produção de pó obtido por três diferentes métodos de secagem. 2010. 139f. Dissertação (Mestrado em Engenharia e Ciência dos Alimentos). Universidade Estadual Paulista Júlio de Mesquita Filho - Instituto de Biociências, Letras e Ciências Exatas. São Paulo, São José do Rio Preto.

MACHADO, I. P. avaliação térmica e desempenho do processo de secagem de misturas de graviola e leite em secador de leito de jorro. 2015. 97f. Dissertação (Mestrado em Engenharia Química) - Centro de Tecnologia, Departamento de Engenharia Química, Programa de PósGraduação em Engenharia Química, Universidade Federal do Rio Grande do Norte, Natal.

MEDEIROS, M. F. D. Influência da composição química dos materiais no desempenho do processo de secagem de polpas de frutas em leito de jorro. 2001. 247f. Tese (Doutorado em Engenharia Química) - Centro de Tecnologia, Departamento de Engenharia Química, Programa de Pós-Graduação em Engenharia Química, Universidade Federal do Rio Grande do Norte, Natal.

SOUZA, J. S. Secagem de misturas de polpas de frutas tropicais em leito de jorro. 2009, 156f. Tese (Doutorado em Engenharia Química) - Centro de Tecnologia, Departamento de Engenharia Química, Programa de Pós-Graduação em Engenharia Química, Universidade Federal do Rio Grande do Norte, Natal.

FANG, Z.; BHANDARI, B. Comparing the efficiency of protein and maltodextrin on spray drying of bayberry juice. Food Research International, v. 48, p. 478-483, 2012. 